\section{$\underset{\text { hommes }}{\text { \& migrations }}$}

\section{Hommes \& migrations}

Revue française de référence sur les dynamiques

migratoires

1315 | 2016

Ondes de choc

\title{
Soy Nero
}

Film franco-germano-mexicain de Rafi Pitts

\section{Anaïk Vincent}

\section{Q OpenEdition \\ 1 Journals}

\section{Édition électronique}

URL : http://journals.openedition.org/hommesmigrations/3744

DOI : 10.4000/hommesmigrations.3744

ISSN : 2262-3353

\section{Éditeur}

Musée national de l'histoire de l'immigration

\section{Édition imprimée}

Date de publication : 1 juillet 2016

Pagination : 141-142

ISBN : 978-2-919040-36-0

ISSN : $1142-852 X$

\section{Référence électronique}

Anaïk Vincent, «Soy Nero », Hommes \& migrations [En ligne], 1315 | 2016, mis en ligne le 02 janvier

2017, consulté le 24 septembre 2020. URL : http://journals.openedition.org/hommesmigrations/3744 ; DOI : https://doi.org/10.4000/hommesmigrations.3744 
"Chouf "en arabe, c'est " guetter", "observer. "Contre plongée surlestra jectoires des habitants; au ralenti et en accéléré, rythmée par les paroles incisives d'un moreau de rap. Perchées sur les toits des immeubles, les senti nelles guettent les moindres allées et venues. La caméra les approche de dos, Hs veillent ì la sécurité des réseaux.

Avec une précision quasi documen taire, le réalisateur déerit la vie de cette eité en s'immergeant dans le quo tidien de ses trafiquants. Sofian, en quête de l'assassin de son frère, est viteconfronté ì la hiérarchie, aux rivalités et à la corruption. À la tête du gang impliqué dans le meurtre, Reda, un cä̈l au sang froid, admirablement incarné par Foued Nabba. Fruit d'une riche col

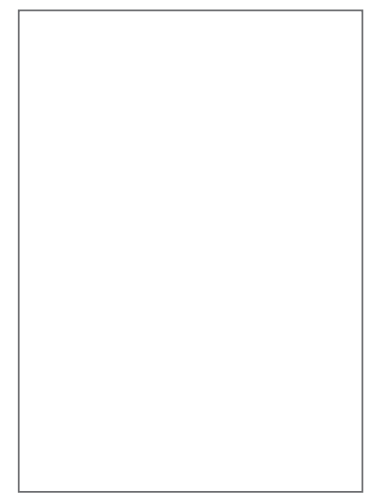

\section{Rafi Pitts}

Soy Nero

Film franco-germanomexicain

En compétition à la dernière édition de la Berlinale, Soy Nero de Rafi Pitts est sorti en salle le 21 septembre dernier. Interdit de résidence sur le territoire iranien pour son œuvre censurée par le régime, le cinéaste franco-iranien, naturellement sensible à cette question de l'immigration, offre une fable géopolitique humaniste sur l'absurdité d'un monde cloisonné par des frontières. Nero (Johnny Ortiz), 19 ans, de parents mexi- taboration avec acteurs amateurs et apprentis comédiens issus des ghet tos marseillais, Chouf ne tombe jamais dans l'écueil des clichés. Pour ce projet, te réalisateur s'est installé à Marseille plusieurs années, a organisé des ateliers de cinéma et, ainsi, a puécrire puis tourner son film en se nourrissant de texpérience de ces jeunes. Les acteurs amateurs s'expriment dans leur argot marseillais avecleur gestuelle propre. comment la corruption et la violence régissent elles la vie de ces quartiers déseuvés? Échec de l'éducation, des politiques culturelles et sociales, de l'in tégration. Constat amer. Dridi dresse le portrait d'une génération désabusée prise dans l'engrenage du banditisme. Anaïs Vincent

cains a été élevé et a grandi aux ÉtatsUnis. Déporté à Mexico, il regagne clandestinement Los Angeles, sa ville. Sa seule alternative pour obtenir le précieux sésame pour enfin devenir un citoyen américain : s'engager dans l'armée américaine. Inspiré de l'histoire vraie de Daniel Torres, le réalisateur aborde avec Soy Nero le sujet brûlant et méconnu des " green card soldiers". Au-delà de cette question d'actualité, il interroge avec une subtile acuité la nécessité d'appartenir à un pays.

Articulation de scènes riches et lourdes de sens comme cette partie de volley habilement chorégraphiée. Les Mexicains renvoient la balle aux Américains sous l'œil menaçant des gardes. La grille métallique qui matérialise la 
frontière comme filet. Ou cette scène de funérailles d'un " green card soldier " qui résonne avec une absurdité assourdissante quand, au cours de la cérémonie, la veuve se fait remettre, lors d'un protocole grotesque, le drapeau américain. Nero profite d'un feu d'artifice pour traverser devant les gardes distraits et revenir illégalement dans son pays.

Johnny Ortis interprète avec une grande justesse l'ambivalence et la complexité de son personnage. II retrouve à Beverly Hills son frère aîné Jesus dans sa villa de luxe financée par le trafic de drogue. Le duo de frères (Johnny Ortiz et lan Casselberry) fonctionne à merveille. Leurs retrouvailles sont bien vite troublées par la réalité amère du quotidien. Pour parvenir à rester sur le sol améri- cain, les alternatives sont limitées. Intégrer les réseaux mafieux ou s'engager. Nero choisit la seconde solution.

On suit alors le jeune homme en poste dans un checkpoint quelque part dans une zone de conflit au Moyen-Orient? En Afghanistan? En Irak? La lumière est aveuglante, l'attente interminable, les hommes perdent la raison, comme le sergent du régiment qui, dans un élan désespéré et suicidaire, marche vers l'ennemi lors d'un assaut. Nero a obtenu la nationalité, mais à quel prix ?

Critique acerbe d'une politique d'immigration américaine instaurée par George W. Bush au lendemain du 11 septembre, Soy Nero, bien plus qu'un film politique, est aussi une fine réflexion philosophique.

Anaïs Vincent 